\title{
Teaching blind nasal intubation in Rwanda
}

\author{
Orlando Hung, MD $\cdot$ Jinbin Zhang, MBBS - Austin Lamb, MD • \\ Christopher Hung, BSc $\cdot$ David Hung, BSc $\cdot$ Ronald Stewart, MD
}

Received: 9 December 2014 / Accepted: 13 January 2015/Published online: 22 January 2015

(c) Canadian Anesthesiologists' Society 2015

\section{To the Editor,}

The editorial by Dr. Wilkinson ${ }^{1}$ offers us an opportunity to further discuss our experience in Rwanda and counter his misimpressions. While recognizing Dr. Wilkinson's vision and support of parturients' health issues in Rwanda, we respectfully disagree with his view of the utility of teaching blind nasal intubation to Rwandan anesthesia trainees and staff. Our disagreement is based on a fundamental principle that "patients come first." Our view of the utility of blind nasal intubation in a resourcepoor environment is based on this cornerstone of medicine.

The basic principle of airway management is to provide adequate oxygenation and ventilation to patients. This principle is necessarily dependent on the tools available to health care providers in their particular environment. In the United Kingdom, for example, there is little need to teach blind nasal intubation, except perhaps in emergency settings. It is probably more useful to teach videolaryngoscopy as these devices are widely available in the developed world. In contrast, it would make little sense to teach videolaryngoscopy or even flexible bronchoscopic intubation in an austere environment with limited resources such as Rwanda, where such tools are not readily available. The value of blind nasal intubation is that it requires only an endotracheal tube.

Editor's Note: The author of the article: Can J Anesth 2014; 61: 975-8, respectfully declined an invitation to submit a reply to the above Letter to the Editor.

O. Hung, MD $(\varangle) \cdot$ J. Zhang, MBBS · A. Lamb, MD .

C. Hung, BSc - D. Hung, BSc $\cdot$ R. Stewart, MD

Department of Anesthesia, Dalhousie University, Queen

Elizabeth II Health Sciences Centre, Halifax, NS, Canada

e-mail: hungorla@dal.ca
Of course, there are limitations in the use of trainingmannequins such as we described. ${ }^{2}$ These limitations, however, do not preclude the value of mannequins for teaching basic airway techniques, particularly as the alternative is a human subject. Teaching airway management using mannequins improves performance ${ }^{3}$ as simulation allows a safe environment for acquiring skills through practice without compromising patient safety. ${ }^{4}$ This is a settled question. We believe that Dr. Wilkinson is simply incorrect in his assertion that teaching blind nasal intubation using mannequins is "antiquated" and "obsolete."

Dr. Wilkinson stated that if one of his family members were pregnant and required an anesthetic for delivery in Rwanda, he would not be comfortable knowing that the caregivers had learned to perform blind nasal intubation on a mannequin in a classroom. This surely is overstated, considering that there are only 12 anesthesiologists in Rwanda serving a population of 11 million people. Anesthesia technicians with limited training in airway management provide most of the anesthesia care in Rwanda. It is likely that his family member would receive an anesthetic provided by an anesthesia technician. Would it not be more reasonable - and safer - to receive the anesthesia from a Rwandan anesthesia technician who has undergone a continuing program of training in airway management that included practice on a mannequin with blind nasal intubation?

One can hardly disagree that it is safer to have a technician trained in airway management than to have one who is untrained. Airway skills are the foundation of all anesthesia management. International organizations, including the World Federation of Societies of Anaesthesiologists, should support Global Outreach Program initiatives to properly train anesthesia personnel in basic airway management skills. 
Improving the quality of anesthesia care in Rwanda, including airway management, will take time and resources. Programs must be designed around the resources widely available to healthcare providers. Of course, there is a role for bringing new technology to advance healthcare in resource-poor countries. A program such as Lifebox ${ }^{\mathrm{A}}$ is one example. Although donating sophisticated airway devices may provide short-term benefit, the ongoing education required and the cost of preventive maintenance in the long term remain problematic. Hence, it is widely recognized that low-cost, safe anesthesia equipment suitable for use in austere environments must be made available to anesthesia providers in these developing countries. ${ }^{5}$ It will likely be years before flexible bronchoscopic intubation and videolaryngoscopy are widely available in resource-poor countries such as Rwanda. Until more advanced resources are available, it is imperative that we use techniques that are known to be effective in teaching lifesaving airway management skills. Such skills should include blind nasal intubation, which we believe ensures that we put patients' needs first.

Conflicts of interest None declared.

\section{References}

1. Wilkinson DJ. Providing quality in anesthesia care in low- and middle-income countries. Can J Anesth 2014; 61: 975-8.

2. Zhang J, Lamb A, Hung O, Hung C, Hung D. Blind nasal intubation: teaching a dying art. Can J Anesth 2014; 61: 1055-6.

3. Kuduvalli PM, Jervis A, Tighe SQ, Robin NM. Unanticipated difficult airway management in anaesthetised patients: a prospective study of the effect of mannequin training on management strategies and skill retention. Anaesthesia 2008; 63: 364-9.

4. Naik VN, Brien SE. Review article: Simulation: a means to address and improve patient safety. Can J Anesth 2013; 60: 192-200.

5. Enright A. Review article: Safety aspects of anesthesia in underresourced locations. Can J Anesth 2013; 60: 152-8.

A Lifebox. Available from URL: http://www.lifebox.org/ (accessed December 2014). 